\title{
Local Group 2 Innate Lymphoid Cells Promote Corneal Regeneration after Epithelial Abrasion
}

Jun Liu, ${ }^{* \dagger \ddagger}$ Chengju Xiao, ${ }^{\ddagger}$ Hanqing Wang, ${ }^{\ddagger}$ Yunxia Xue, ${ }^{\dagger}$ Dong Dong, ${ }^{\dagger}$ Cuipei Lin, ${ }^{\dagger}$ Fang Song, ${ }^{\ddagger}$ Ting Fu, ${ }^{\dagger}$ Zhaorui Wang, Jiansu Chen, ${ }^{\dagger}$ Hongwei Pan, ${ }^{\dagger}$ Yangqiu $\mathrm{Li}^{,},{ }^{\ddagger}$ Dongqing Cai, ${ }^{\ddagger}$ and $\mathrm{Zhijie} \mathrm{Li}^{\dagger \dagger \uparrow}$

From the Integrated Chinese and Western Medicine Postdoctoral Research Station, * Jinan University, Guangzhou; the International Ocular Surface Research Center and Institute of Ophthalmology, ${ }^{\dagger}$ Jinan University Medical School, Guangzhou; the Key Laboratory for Regenerative Medicine, ${ }^{\ddagger}$ Ministry of Education, Jinan University, Guangzhou; the Department of Medical Images, ${ }^{\S}$ The Third People’s Hospital, Puyang; and the Henan Eye Institute, "Henan Eye Hospital, Henan Provincial People's Hospital and Zhengzhou University People's Hospital, Zhengzhou, China

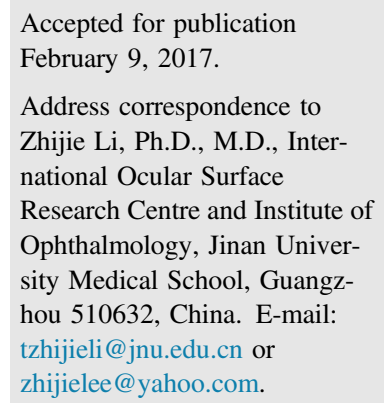

\begin{abstract}
Corneal injuries and infections are the leading cause of blindness worldwide. Thus, understanding the mechanisms that control healing of the damaged cornea is critical for the development of new therapies to promptly restore vision. Innate lymphoid cells (ILCS) are a recently identified heterogeneous cell population that has been reported to orchestrate immunity and promote tissue repair in the lungs and skin after injury. However, whether ILCs can modulate the repair process in the cornea remains poorly understood. We identified a population of cornea-resident group 2 ILCs (ILC2s) in mice that express CD127, T1/ST2, CD90, and cKit. This cell population was relatively rare in corneas at a steady state but increased after corneal epithelial abrasion. Moreover, ILC2s were maintained and expanded locally at a steady state and after wounding. Depletion of this cell population caused a delay in corneal wound healing, whereas supplementation of ILC2s through adoptive transfer partially restored the healing process. Further investigation revealed that IL-25, IL-33, and thymic stromal lymphopoietin had critical roles in corneal ILC2 responses and that $\mathrm{CCR}^{-}$corneal macrophages were an important producer of IL-33 in the cornea. Together, these results reveal the critical role of cornea-resident ILC2s in the restoration of corneal epithelial integrity after acute injury and suggest that ILC2 responses depend on local induction of IL-25, IL-33, and thymic stromal lymphopoietin. (Am J Pathol 2017, 187: 1313-1326; http://dx.doi.org/10.1016/j.ajpath.2017.02.010)
\end{abstract}

According to the World Health Organization, blindness, which can be caused by corneal disease, diabetic retinopathy, dry-eye syndrome, and contact lens-related keratitis, affects up to 39 million people globally. Among these conditions, corneal disease is the most important cause of blindness in developing countries and is the second leading cause of blindness worldwide after cataracts. ${ }^{1}$ Most corneal diseases are caused by corneal injuries and corneal infections. ${ }^{2}$ Injuries to the cornea are commonly caused by abrasions, exposure to chemicals, contact lens use, foreign bodies, and UV light. Modern refractive corneal surgery can further amplify these problems. Thus, clear understanding of the mechanisms controlling wound healing in the cornea is critical for the development of new therapies to promptly restore vision.

Healing of damaged tissue is a complex process that involves inflammation, cell migration and proliferation, protein synthesis, wound closure, and remodeling. ${ }^{3-5}$ Failure to regulate any of these healing procedures can impede the resolution of inflammation and recovery of tissue integrity. Although some mechanisms that involve corneal wound healing have been reported, ${ }^{6-11}$ many aspects are still not well understood. Innate lymphoid cells (ILCs), a recently recognized heterogeneous cell population, participate in immune regulation and wound healing. ${ }^{12,13}$ Although ILCs resemble $\mathrm{B}$ and $\mathrm{T}$ cells in terms of morphology, they do not express clonotypic antigen receptors, and their development does not require recombination-activating genes (Rag1 or Rag2). The three

Supported by National Natural Science Foundation of China grants 39970250, 30772387, and 81070703 (Z.L.).

Disclosures: None declared. 
groups of ILCs-ILC1s, ILC2s, and ILC3s-are derived from a common lymphoid progenitor but differ in terms of cytokine secretion and effector function. ${ }^{14-20}$ Of these three groups, ILC2s can respond to IL-25, IL-33, and thymic stromal lymphopoietin (TSLP) expressed by injured tissues, and IL-33 has been reported to play a crucial role in repairing damaged or inflamed lung and skin tissues by inducing secretion of amphiregulin (AREG), a type of epidermal growth factor. ${ }^{21}$ Thus, an investigation of the distribution and function of ILC2s in the cornea is important to fully understand the corneal wound healing process.

It is a traditional belief that the maintenance of immune cells in the peripheral tissues depends on the continuous contribution of progenitor cells from bone marrow. Although this theory has been challenged by recent findings that some tissue-resident immune cells can renew through local proliferation, ${ }^{22,23}$ many details remain unknown because there are distinct maintenance mechanisms that depend on the presence of various tissue-resident immune cells and physiopathologic conditions. For example, cardiac macrophages can self-renew by local proliferation at steady state, but when cardiac macrophages are depleted or the heart is inflamed, the maintenance mechanisms of cardiac macrophages change and rely on recruitment and differentiation of blood monocytes. ${ }^{24}$ Moreover, Gasteiger et $\mathrm{al}^{25}$ found that at steady state, ILCs in the small intestine, salivary glands, lungs, and mesenteric lymph nodes are maintained through local proliferation. In contrast, after a parasitic infection, a portion of the ILCs in the small intestine are replaced by hematopoietic cells from the bone marrow, whereas ILCs in the salivary glands, lungs, and mesenteric lymph nodes remain unaffected.

It is unclear whether ILC2s exist in the cornea, if they have a role in corneal epithelial regeneration, or how this population of cells might be maintained. We confirm the presence of ILC2s in the corneal limbus. Using a corneal epithelial wound-healing model, together with the depletion of corneal ILC2s and adoptive transfer of ILC2s, we found that corneal ILC2s participated in corneal wound healing, and their roles depend on the local induction of IL-25, IL33 , and TSLP, and of these, IL-33 can be produced by $\mathrm{CCR} 2^{-}$corneal macrophages. Finally, we found that longterm maintenance of corneal ILC2s depends primarily on local proliferation rather than the contribution of bone marrow progenitor cells.

\section{Materials and Methods}

\section{Animals}

Specific pathogen free female C57BL/6 mice were bought from the Medical Experimental Animal Center (Guangdong, China) and were free of eye disease. Rosa-yellow fluorescent protein (YFP) male mice were bought from the Shanghai South Model Biological Technology Limited Company (Shanghai, China). These animals were raised at the Jinan University Animal Center. Experiments were performed using mice aged 7 to 8 weeks. One cornea was harvested from each mouse. All animal protocols were approved by the Jinan University Laboratory Animal Committee on Animal Welfare. All the animal treatments were performed in accordance with the Association for Research in Vision and Ophthalmology's Statement for the Use of Animals in Ophthalmology and Vision Research and the guidelines of the Animal Experimental Committee at Jinan University. The animals were anesthetized through inhalation of $2 \%$ isoflurane and were euthanized using a lethal dose of $\mathrm{CO}_{2}$ and cervical dislocation.

\section{Corneal Wound Healing Model}

Central corneal abrasion was performed as previously described. ${ }^{6-11}$ In brief, anesthetized mice were placed under the dissecting microscope. A trephine with a 2-mm diameter was used to mark the traumatic zone at the middle of the mouse corneal epithelium, and the marked epithelial cell layer was scraped with a golf club-like scraper. The wound region was stained with sodium fluorescein. An image was taken by the camera on the dissecting microscope, and then this image was loaded into Photoshop CS4 to calculate the area of the stained region. The wound healing process was assessed by observing the change in the area of the stained region.

\section{Bone Marrow Transplantation Model}

Recipient female mice drank gentamicin water for 1 week before administration of a 5-Gy dose of radiation to destroy their hematopoietic systems. To avoid eye tissues of mice being affected by radiation, each eye was covered with a lead cover. Within 4 hours after irradiation, the recipient female mice were given the bone marrow of Rosa-YFP male mice through tail vein injection. The recipient mice were continuously provided with gentamicin water. Two weeks after the transfer, peripheral blood leukocytes were analyzed to determine the expression of the Sry gene by PCR, and the percentage of $\mathrm{YFP}^{+}$cells was analyzed using flow cytometry to assess whether bone marrow transplantation was successful.

\section{Depleting Target Cells or Blocking the Specific Molecules}

Anti-CD90 antibody can be used to effectively deplete ILCs. ${ }^{21,26}$ Each eye of the mice was subconjunctivally injected with $5 \mu \mathrm{L}$ of rat anti-mouse CD90.2 monoclonal antibodies $(4 \mu \mathrm{g} / \mu \mathrm{L})$ five times (once every other day). The control group was injected with $4 \mu \mathrm{g} / \mu \mathrm{L}$ of isotype rat IgG2b.

To block corneal IL-25, IL-33, and TSLP, each eye was subconjunctivally injected with $5 \mu \mathrm{L}$ of rat anti-mouse 
IL-25, IL-33, or TSLP antibody $(1 \mu \mathrm{g} / \mu \mathrm{L}) 10$ times (once every other day). The control group was injected with $1 \mu \mathrm{g} / \mu \mathrm{L}$ of rat IgG2a.

To deplete CCR2 $2^{-}$corneal macrophages, $5 \mu \mathrm{L}$ of dialyzed rat anti-mouse CSF1R antibody $(1 \mu \mathrm{g} / \mu \mathrm{L})$ were

Table 1 Antibodies Used in This Study

\begin{tabular}{|c|c|c|}
\hline Antibody & Company & $\begin{array}{l}\text { Catalog } \\
\text { number }\end{array}$ \\
\hline Rat anti-mouse CD90.2 antibody & BioXCell & BE0066 \\
\hline Rat IgG2b & BioXCell & BE0090 \\
\hline Rat anti-mouse IL-25 antibody & R\&D Systems & MAB13992 \\
\hline Rat anti-mouse IL-33 antibody & R\&D Systems & AF3626 \\
\hline Rat anti-mouse TSLP antibody & R\&D Systems & MAB555 \\
\hline Rat IgG2a & R\&D Systems & MAB006 \\
\hline Rat anti-mouse CSF1R antibody & eBioscience & $14-1152-82$ \\
\hline Rat IgG2a & eBioscience & $16-4321-82$ \\
\hline $\begin{array}{l}\text { Anti-mouse Lineage Cocktail } \\
\text { antibodies FITC }\end{array}$ & Biolegend & 133301 \\
\hline Anti-mouse CD127 antibody APC & BD Biosciences & 564175 \\
\hline Anti-mouse CD16/32 antibody & eBioscience & $14-0161-85$ \\
\hline Anti-mouse CD45 antibody FITC & BD Biosciences & 553080 \\
\hline $\begin{array}{l}\text { Anti-mouse Lineage Cocktail } \\
\text { antibodies BV421 }\end{array}$ & Biolegend & 133311 \\
\hline $\begin{array}{l}\text { Anti-mouse IL-33R (T1/ST2) } \\
\text { antibody Percp-Cy5.5 }\end{array}$ & Biolegend & 145312 \\
\hline $\begin{array}{l}\text { Anti-mouse CD4 antibody } \\
\text { PE-Cyanine7 }\end{array}$ & eBioscience & $25-0041$ \\
\hline $\begin{array}{l}\text { Anti-mouse NKp46 antibody } \\
\text { PE-Cyanine7 }\end{array}$ & eBioscience & $25-3351$ \\
\hline $\begin{array}{l}\text { Anti-mouse cKit antibody } \\
\text { PE-Cyanine7 }\end{array}$ & eBioscience & $25-1171$ \\
\hline $\begin{array}{l}\text { Anti-mouse CD90.2 antibody } \\
\text { APC-eFluor } 780\end{array}$ & eBioscience & 47-0902 \\
\hline $\begin{array}{l}\text { Anti-mouse CD64 antibody } \\
\text { BV421 }\end{array}$ & Biolegend & 139309 \\
\hline Anti-mouse CCR2 antibody APC & R\&D Systems & FAB5538A \\
\hline $\begin{array}{l}\text { Anti-mouse/rat Ki-67 antibody } \\
\text { PE-Cyanine7 }\end{array}$ & eBioscience & $25-5698$ \\
\hline $\begin{array}{l}\text { Anti-goat IgG secondary } \\
\text { antibody-PE }\end{array}$ & R\&D Systems & F0107 \\
\hline FITC Rat IgG2b, $\kappa$ Isotype Control & BD Biosciences & 556923 \\
\hline $\begin{array}{l}\text { Brilliant Violet } 421 \text { Rat IgG2b, } \\
\kappa \text { Isotype }\end{array}$ & Biolegend & 400639 \\
\hline APC Rat IgG2a, $\kappa$ Isotype Control & Biolegend & 400511 \\
\hline $\begin{array}{l}\text { Rat IgG2b K Isotype Control } \\
\text { PE-Cyanine7 }\end{array}$ & eBioscience & $25-4031-81$ \\
\hline $\begin{array}{l}\text { Rat IgG2a K Isotype Control } \\
\text { PE-Cyanine7 }\end{array}$ & eBioscience & $25-4321-81$ \\
\hline PE Rat IgG2a, $\kappa$ Isotype Control & BD Biosciences & 553930 \\
\hline $\begin{array}{l}\text { Rat IgG2B APC-conjugated } \\
\text { Isotype Control }\end{array}$ & R\&D Systems & IC013A \\
\hline $\begin{array}{l}\text { Brilliant Violet } 421 \text { Mouse IgG1, } \\
\kappa \text { Isotype }\end{array}$ & Biolegend & 400157 \\
\hline Normal Goat IgG Control & R\&D Systems & $A B-108-C$ \\
\hline $\begin{array}{l}\text { Rat IgG2a K Isotype Control } \\
\text { PE-Cyanine7 }\end{array}$ & eBioscience & $25-4321-81$ \\
\hline
\end{tabular}

APC, allophycocyanin; FITC, fluorescein isothiocyanate; TSLP, thymic stromal lymphopoietin.
Table 2 PCR Primers Used in This Study

\begin{tabular}{lll}
\hline Gene & Primer pair & \\
\hline Areg & Forward & $5^{\prime}$-ATTACTTTGGTGAACGGTGT-3' \\
& Reverse & $5^{\prime}$-GATTCAACTTTTACCCTGCAT-3' \\
Il25 & Forward & $5^{\prime}$-GAGTTGGACAGGGACTTGAA-3' \\
& Reverse & $5^{\prime}$-AGGTGGTGAGCATGACTAAG-3' \\
Il33 & Forward & $5^{\prime}$-TACTGCATGAGACTCCGTTC-3' \\
& Reverse & $5^{\prime}$-CTTCATGCTTGGTACCCGAT-3' \\
Islp & Forward & $5^{\prime}$-TGCACACACCTTACTCTAGG-3' \\
& Reverse & $5^{\prime}$-TGATCTCAGCAGTTTCTCCC-3' \\
Il4 & Forward & $5^{\prime}$-AGCTAGTTGTCATCCTGCTC-3' \\
& Reverse & $5^{\prime}$-TGTGACCTCGTTCAAAATGC-3' \\
Il5 & Forward & $5^{\prime}$-GGGGTACTGTGGAAATGCTA-3' \\
& Reverse & $5^{\prime}$-TTGTGGGGTTTTGCATCTG-3' \\
Il9 & Forward & $5^{\prime}$-GCTTGTGTCTCTCCGTCCCAA-3' \\
& Reverse & $5^{\prime}$-TTCAACTATCCTTTTCACCCGAT-3' \\
Il13 & Forward & $5^{\prime}$-GCAACATCACACAAGACCAG-3' \\
& Reverse & $5^{\prime}$-AGGCCATGCAATATCCTCTG-3' \\
Sry & Forward & $5^{\prime}$-AGGTGGAAAAGCCTTACAGAA-3' \\
& Reverse & $5^{\prime}$-GGATATCAACAGGCTGCCAAT-3' \\
Gapdh & Forward & $5^{\prime}$-CAAGGACACTGAGCAAGAG-3' \\
& Reverse & $5^{\prime}$-TGCAGCGAACTTTATTGATG-3' \\
\hline
\end{tabular}

subconjunctivally injected 10 times (once every other day). The control group was injected with $1 \mu \mathrm{g} / \mu \mathrm{L}$ of isotype rat IgG2a. Details regarding antibodies are given in Table 1. To deplete CCR2 ${ }^{+}$corneal macrophages, $1 \mathrm{mg}$ of the CCR2 antagonist BMS CCR2 22 (R\&D Systems, Minneapolis, MN: catalog number 3129) was dissolved in $1 \mathrm{~mL}$ of absolute ethyl alcohol. The stock solution was adjusted with saline to $0.1 \mu \mathrm{g} / \mu \mathrm{L}$, and then each mouse was injected i.p. with $10 \mu \mathrm{g}$ per $20 \mathrm{~g}$ of body weight (10 times, once every other day). The control group was injected with the diluent of BMS CCR2 22.

\section{Immunostaining}

Immunostaining was performed on whole-mount corneas as previously described. $^{6-11}$ In brief, after the mice were euthanized, the eyeballs were detached and fixed in $4 \%$ paraformaldehyde for 1 hour. The fixed eyeballs were placed in phosphate-buffered saline (PBS) and clipped under a dissecting microscope, leaving the whole corneas and limbi. The corneas were blocked with $2 \%$ bovine serum albumin for 15 minutes and then permeabilized with $0.1 \%$ Triton X-100/2\% bovine serum albumin for 15 minutes. The treated corneas were then incubated with a mixture of antibodies (dilution 1:100), including anti-mouse Lineage Cocktail (CD3e, Ly6G/Ly6C, CD11b, CD45R/B220, and TER-119) antibodies conjugated with fluorescein isothiocyanate (FITC) and anti-mouse CD127 antibody conjugated with allophycocyanin (APC) at $4^{\circ} \mathrm{C}$ overnight. Details regarding antibodies are given in Table 1. After being washed three times in PBS (5 minutes per wash), the corneas were placed on glass slides and radially cut to flatten them. Fluorescent mounting media that contained $1 \mu \mathrm{mol} / \mathrm{L}$ 
A
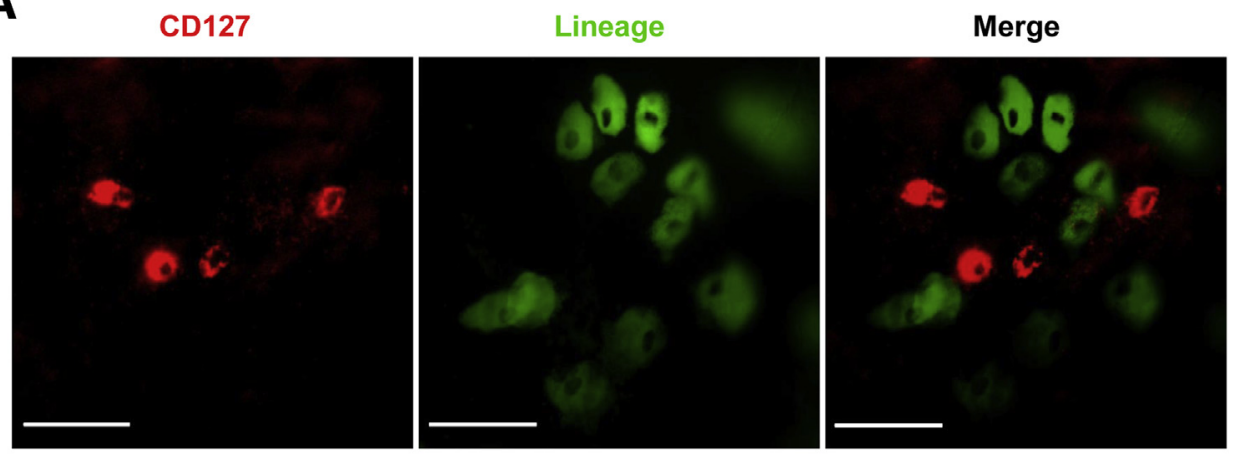

B
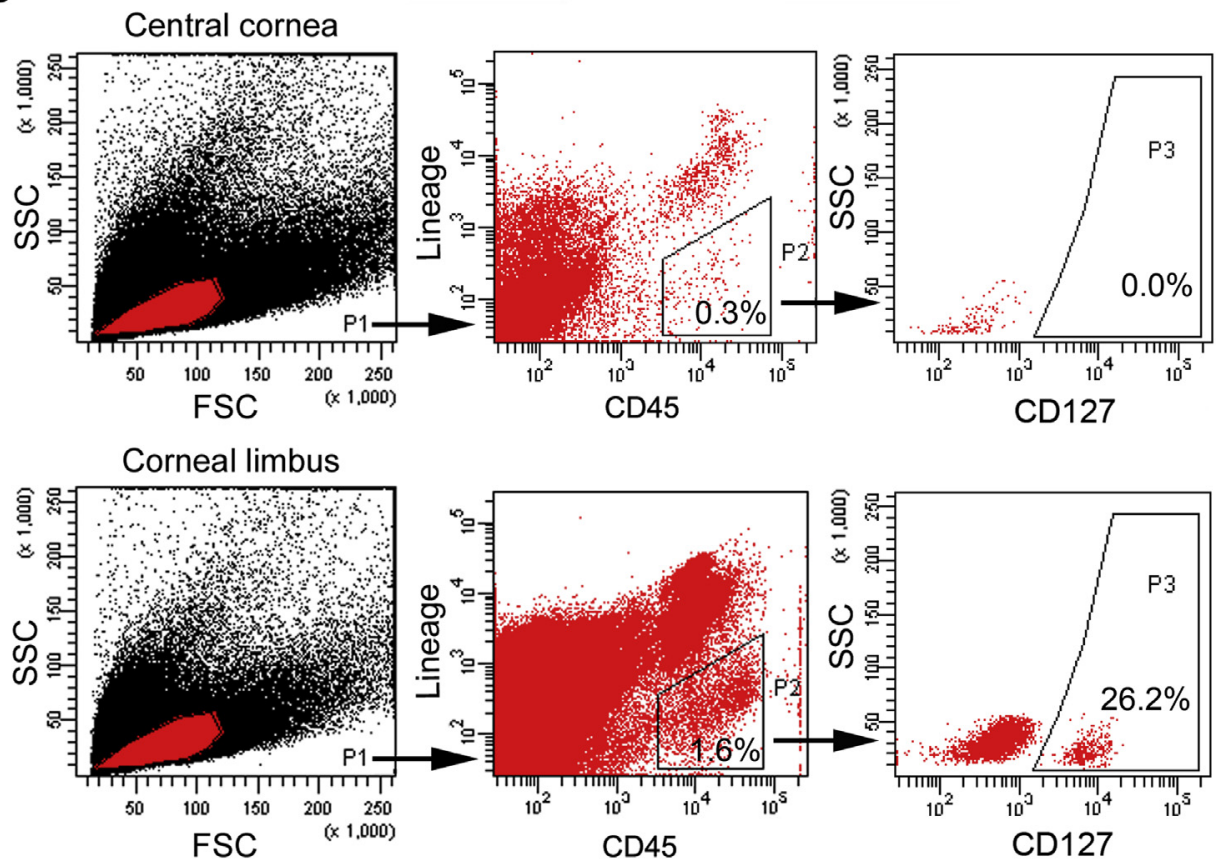

CD45

CD45+Lin-CD127+
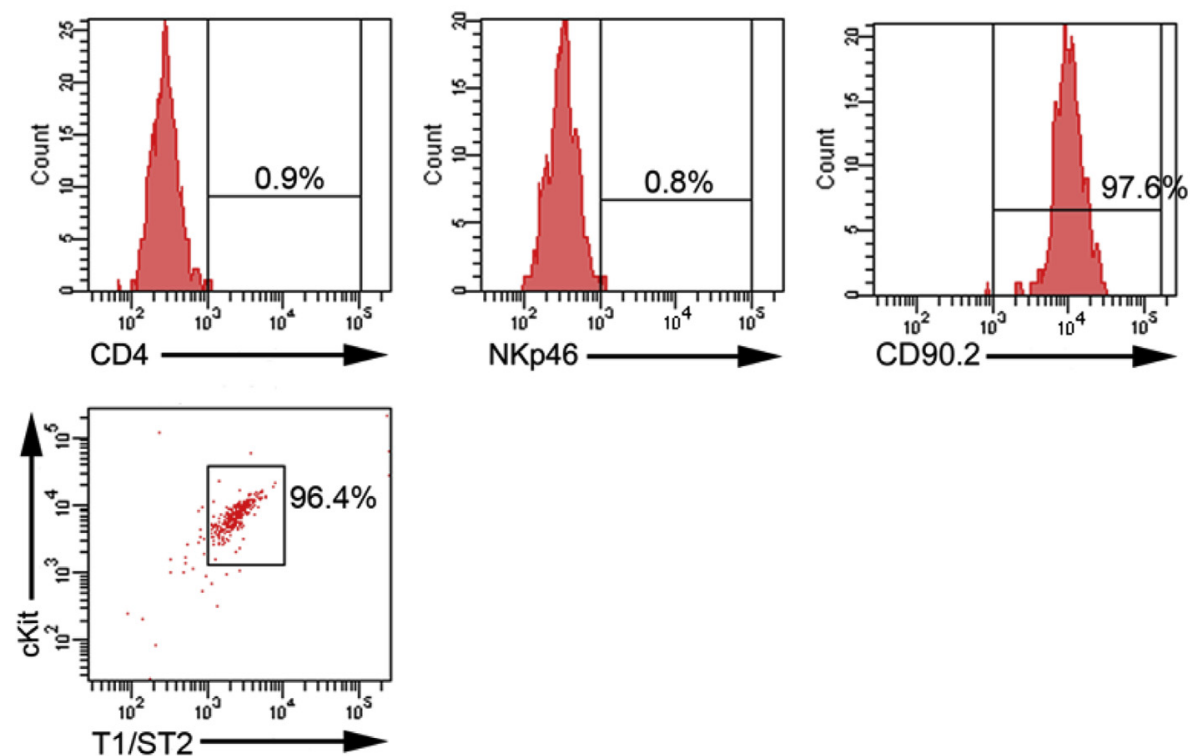
of DAPI (Sigma-Aldrich, St. Louis, MO; catalog number 28718-90-3) was placed on the corneas. Image analysis of the corneas was performed with the DeltaVision microscopy imaging system (Applied Precision, Issaquah, WA).

\section{Flow Cytometric Analysis}

Flow cytometric analysis was performed as previously described. ${ }^{27}$ To avoid the contamination by blood cells, adult C57BL/6 mice were flushed with PBS through the left ventricle. The detached eyeballs were placed in PBS and clipped under a dissecting microscope, leaving the whole corneas and limbi. The corneal tissues were cut into pieces and digested with $0.2 \%$ collagenase type I (Sigma-Aldrich, catalog number C0130) for 1.5 to 2 hours. Digested cells were passed through a $75-\mu \mathrm{m}$ filter and washed twice with PBS. The resulting cell pellet was resuspended and blocked in Flow Cytometry Staining Buffer (eBioscience, Waltham, MA; catalog number 00-4222) containing anti-mouse CD16/32 antibody at room temperature for 10 minutes followed by incubation at room temperature for 30 minutes with a mixture of the following antibodies (dilution 1:100): anti-mouse CD45 antibody conjugated with FITC, anti-mouse Lineage Cocktail (CD3, Ly6G/Ly6C, CD11b, CD45R/B220, and TER-119) antibodies conjugated with Brilliant Violet 421, anti-mouse CD127 antibody conjugated with APC, antimouse IL-33R (T1/ST2) antibody conjugated with PercpCy5.5 (anti-mouse CD4 antibody conjugated with PECyanine7, anti-mouse NKp46 antibody conjugated with PE-Cyanine7, or anti-mouse cKit antibody conjugated with PE-Cyanine7), and anti-mouse CD90.2 antibody conjugated with APC-eFluor 780. Corneal macrophages were analyzed by staining a mixture of the following antibodies (dilution 1:100): FITC-conjugated anti-mouse CD45 antibody, antimouse CD64 antibody conjugated with Brilliant Violet 421, and APC-conjugated anti-mouse CCR2 antibody.

For the detection of the intracellular antigens Ki-67 and IL-33, cell suspensions were fixed in $4 \%$ paraformaldehyde for 30 minutes and permeabilized with $0.1 \%$ Triton X-100 for 10 minutes. After being washed twice in PBS, the cell suspensions were incubated with anti-mouse/rat $\mathrm{Ki}-67$ antibody-conjugated with PE-Cyanine7 (dilution 1:100) for 30 minutes or goat anti-mouse IL-33 antibody (dilution 1:100) for 30 minutes. Then these IL-33-stained cells were washed twice in PBS and followed by incubation with PEconjugated anti-goat IgG secondary antibody (dilution $1: 100)$ at room temperature for 30 minutes. Details regarding antibodies are given in Table 1. The Anti-Rat and
Anti-Hamster Igк/Negative Control Compensation Particles Set (BD Biosciences, Franklin Lakes, NJ; catalog number 552845) was used to adjust the fluorescence compensation before flow cytometric analysis, which was performed using the BD FACSVerse (BD Biosciences). The gating strategies in this study were justified by appropriate isotype control antibodies, which are provided in Supplemental Figure S1.

\section{Adoptive Transfer of ILC2s}

Lung cell suspensions were incubated with a mixture of antibodies (dilution 1:100), including anti-mouse CD45 antibody conjugated with FITC, anti-mouse Lineage cocktail (CD3, Ly6G/Ly6C, CD11b, CD45R/B220, and TER-119) conjugated with Brilliant Violet 421, anti-mouse CD127 antibody conjugated with APC, and anti-mouse IL-33R (T1/ST2) antibody conjugated with Percp-Cy5.5, at room temperature for 30 minutes. Details regarding antibodies are given in Table 1. Cell suspensions were sorted by flow cytometry using the BD FACSAria (BD Biosciences) to obtain CD45 ${ }^{+} \mathrm{Lin}^{-} \mathrm{CD} 127^{+}$ T1/ST2 ${ }^{+}$ILC2s. Sorted ILC2s were labeled with green fluorescence by incubation with carboxyfluorescein diacetate succinimidyl ester (CFDA-SE) (Vybrant CFDA-SE Cell Tracer Kit; Invitrogen, Carlsbad, CA; catalog number $\mathrm{V} 12883$ ) at $37^{\circ} \mathrm{C}$ for 30 minutes. Then, $500 \mu \mathrm{L}$ of cell suspension (adjusted to $1 \times 10^{4} / \mathrm{mL}$ with saline) was transferred to anti-CD90.2 antibody-treated mice by tail vein injection.

\section{Administration of Recombinant Amphiregulin}

Anti-CD90.2 antibody-treated mice were given $5 \mu \mathrm{L}$ of recombinant mouse amphiregulin protein $(1 \mu \mathrm{g} / \mu \mathrm{L})(\mathrm{R} \& \mathrm{D}$ Systems, catalog number 989-AR/CF) ocularly by drop (4 times, one time every 6 hours after corneal wounding).

\section{Transcript Amplification in Corneal ILC2s}

Corneal cell suspensions were incubated with a mixture of the following antibodies (dilution 1:100): anti-mouse CD45 antibody conjugated with FITC, anti-mouse Lineage Cocktail (CD3, Ly6G/Ly6C, CD11b, CD45R/B220, and TER-119) antibodies conjugated with Brilliant Violet 421, anti-mouse CD127 antibody conjugated with APC, and anti-mouse IL-33R (T1/ST2) antibody conjugated with Percp-Cy5.5, at room temperature for 30 minutes. Details regarding antibodies are given in Table 1. Cell suspensions were then sorted by flow cytometry (BD FACSAria) to isolate CD45 ${ }^{+} \mathrm{Lin}^{-} \mathrm{CD} 127^{+}$ $\mathrm{T}_{1 / \mathrm{ST}}{ }^{+}$cells. The REPLI-gWTA Single Cell Kit (catalog

\footnotetext{
Figure 1 Identification of innate lymphoid cells (ILCS) in corneal limbi. A: Anti-CD127 allophycocyanin (in red) and anti-Lineage Cocktail fluorescein isothiocyanate (in green) co-staining of the corneal limbus. The merged image shows that CD127-positive cells are negative for the cell lineage markers CD3, B220, Ly6G/Ly6C, CD11b, and TER-119. B: Identification of CD45 ${ }^{+} \mathrm{Lin}^{-} \mathrm{CD} 127^{+}$ILCs in the central corneas and corneal limbi using flow cytometry. The P2-gated cells are $\mathrm{CD}_{4} 5^{+} \mathrm{Lin}^{-}$, and some of these CD45 ${ }^{+} \mathrm{Lin}^{-}$cells in the corneal limbi are CD127 positive (P3 gated cells). These CD45 ${ }^{+}$Lin ${ }^{-}$CD127 $7^{+}$cells are CD4 and NKp46 negative and CD90.2, cKit, and T1/ST2 positive. The gating strategies are justified by appropriate isotype control antibodies, which are provided in the Supplemental Figure S1A. Scale bar $=50 \mu \mathrm{m}$. FSC, forward scatter; SSC, side scatter.
} 

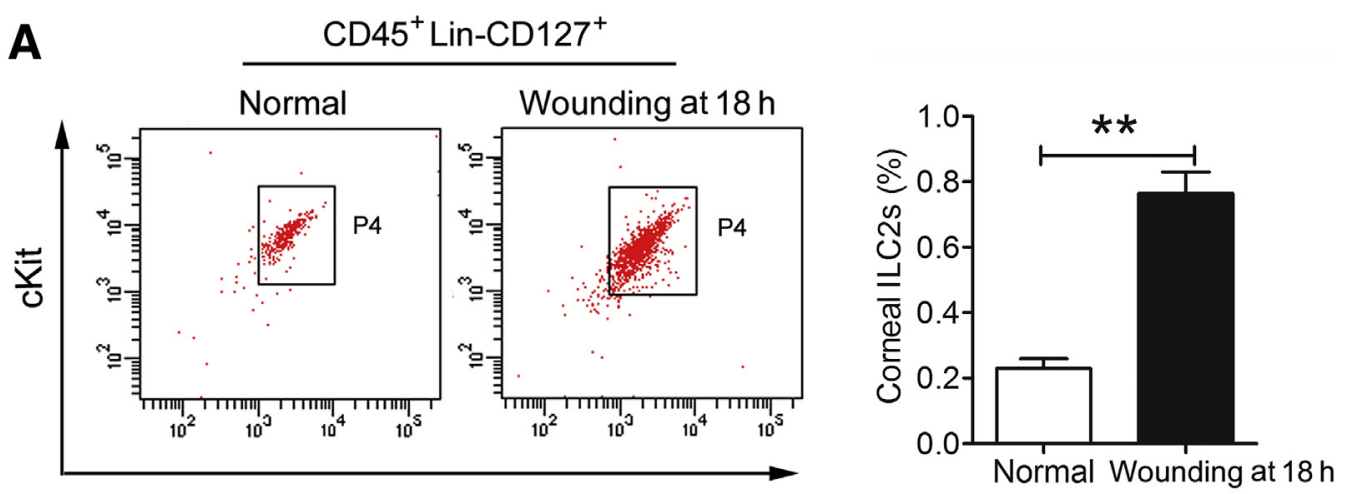

T1/ST2
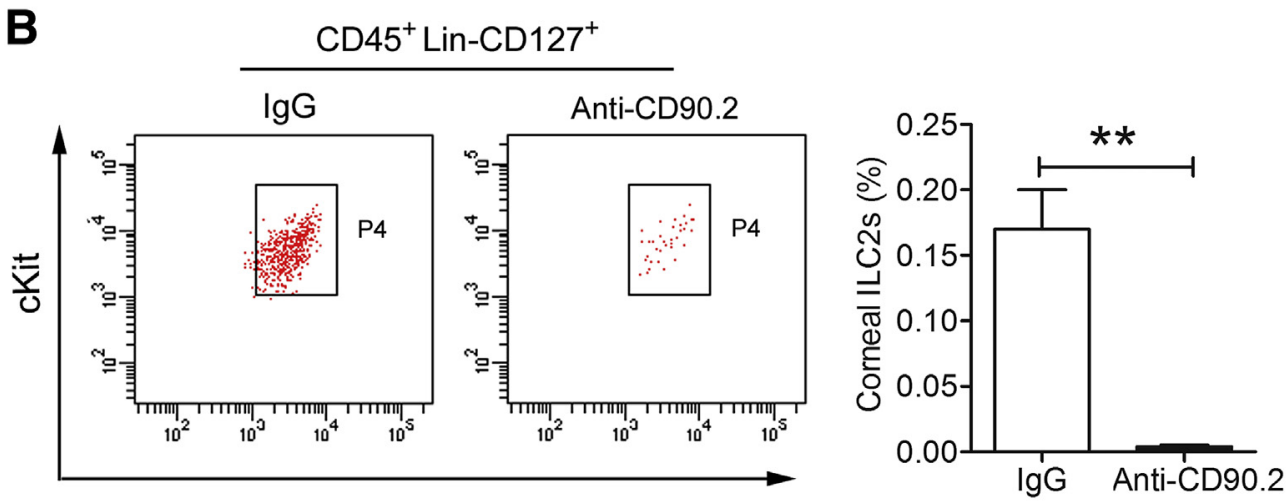

T1/ST2

Figure 2 Changes in the percentage of innate lymphoid cells (ILCS) in corneal cells, including central corneal and corneal limbal cells, after corneal epithelial abrasion or anti-CD90.2 antibody treatment. A: The percentage of ILC2s in corneal cells from normal mice and mice 18 hours after corneal epithelial wounding. B: The percentage of ILC2s in cornea cells was measured after five subconjunctival injections of isotype IgG or anti-CD90.2 antibody. Data are expressed as means \pm SD. $n=3$ independent experiments, 20 mice per experiment (A and $\mathbf{B})$. ${ }^{* *} P<0.01$.

number 150063; Qiagen, Hilden, Germany) was used for whole transcriptome amplification of the sorted cells.

\section{PCR}

Corneal tissues were cut into pieces, placed in Buffer RZ (catalog number RK145; Tiangen, Beijing, China) and smashed with a TissueRuptor (Qiagen). Total RNA was extracted using the RNAsimple Total RNA Kit (catalog number DP419; Tiangen), and cDNA was generated using the ReverTra Ace real-time quantitative PCR (qPCR) kit (catalog number FSQ-101; Toyobo, Osaka, Japan). Finally, the Thunderbird SYBR qPCR Mix (catalog number QPS-201; Toyobo) was used to detect target gene expression in corneal cDNA and the amplified transcriptome of sorted ILC2s. Premix Tag (catalog number RR902Q; Takara, Tokyo, Japan) was used to detect Sry gene expression in the genomic DNA of peripheral blood leukocytes. The PCR primers used in this study are listed in Table 2. 2- $\Delta \Delta \mathrm{Ct}$ method was used to analyze gene expression, and the expression of each gene was normalized to $G A P D H$ expression and compared relative to indicated group.

\section{Statistical Analysis}

The results are presented as the means \pm SD. For comparisons between groups, an unpaired $t$-test was performed. Statistical significance was set at $P<0.05$.

\section{Results}

\section{ILC2s Are Present in Mouse Corneal Limbi}

All members of the ILC family are characterized by a classic lymphoid cell morphology and expression of CD127 in the absence of the cell-surface molecules CD3, B220, Ly6G/ Ly6C, CD11b, and TER-119, which identify other immune cell types. ${ }^{28,29}$ ILCs are thus defined as cell lineage marker-negative $\left(\mathrm{Lin}^{-}\right)$cells and are referred to here as $\mathrm{Lin}^{-} \mathrm{CD} 127^{+}$ILCs. In our study, immunostaining of the cornea and flow cytometric analysis revealed a small number of $\mathrm{Lin}^{-} \mathrm{CD} 127^{+}$ILCs in the corneal limbi of 7- to 8-week-old female C57BL/6 mice (Figure 1, A and B). Further flow cytometric analysis revealed that these limbal $\mathrm{Lin}^{-} \mathrm{CD} 127^{+}$ILCs did not express CD4 or NKp46 (0.9\% and $0.8 \%$ positive cells, respectively) (Figure $1 \mathrm{~B}$ ) and thus 

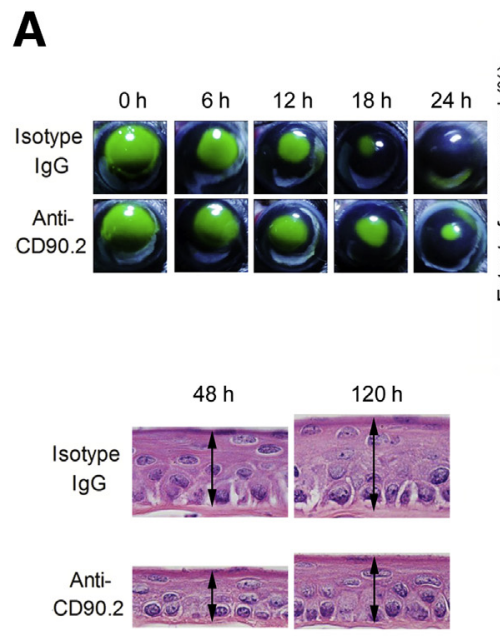
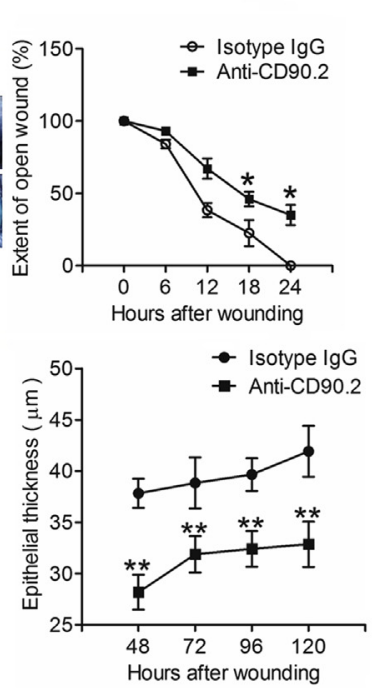

$\mathbf{B}_{\text {ssops }}$

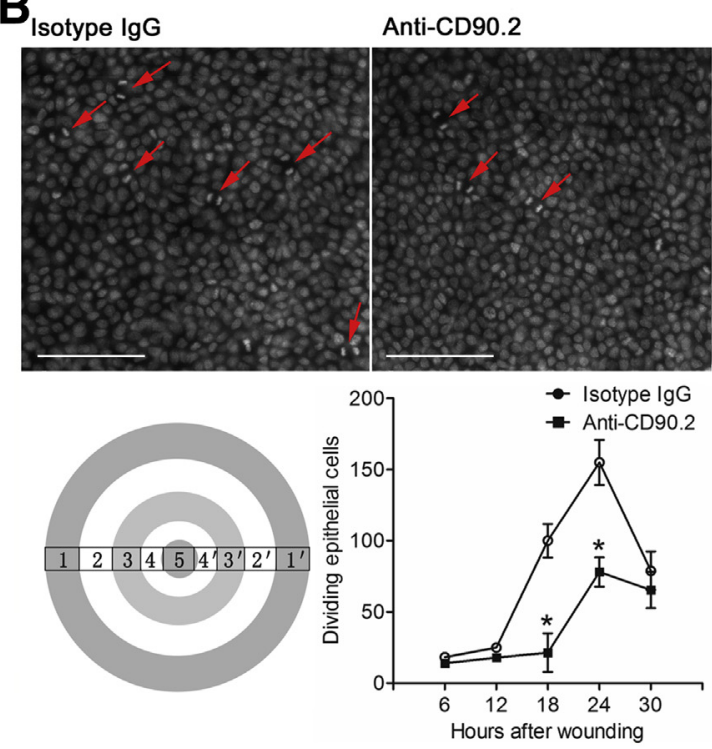

Figure 3 The effect of anti-CD90.2 antibody treatment on corneal epithelial wound healing. A: A portion of corneal epithelial was abraded after five subconjunctival injections of isotype IgG or anti-CD90.2 antibody. Corneal epithelial wounds were stained with sodium fluorescein (upper left images), and the stained area was measured using Photoshop CS4. The following curve graph represents a dynamic change in the percentage of the open wound after corneal epithelial wounding. The percentage of the open wound was obtained by dividing the original wound area by the wound area at each time point. Corneal epithelium was stained with hematoxylin and eosin (lower left images), and the thickness of epithelium (double arrows) was measured using Photoshop CS4. The curve seen on the graph represents a dynamic change of epithelial thickness from 48 to 120 hours after wounding. B: Corneas from isotype IgG and anti-CD90.2 antibody-treated mice were stained with DAPI. The red arrows marking coupled cell nuclei represent dividing epithelial cells. Dividing epithelial cells were counted in nine microscopic fields across the cornea from limbus to limbus (zone 1 to zone $1^{\prime}$ ), each field was viewed using a 40× objective lens (approximately $0.53 \mathrm{~mm}$ ), and the total cell number was plotted against the time after wounding. Data are expressed as means \pm SD. $n=6$ mice at each time point (A and $\mathbf{B}) .{ }^{*} P<0.05,{ }^{*} P<0.01$. Scale bar $=75 \mu \mathrm{m}$.

are distinct from $\mathrm{CD} 4^{+} \mathrm{LTi}$ cells and $\mathrm{NKp} 46^{+}$ILCs. ${ }^{30}$ These ILCs expressed ILC2-related surface antigens, including CD90 (97.6\% of cells), T1/ST2, and cKit/CD117 (96.4\% of cells) (Figure 1B). Therefore, the $\mathrm{Lin}^{-}$ILCs identified in the cornea were considered to be ILC2s.

\section{Anti-CD90.2 Antibody Treatment Delays Corneal Wound Healing}

ILC2s are known to play an important role in maintaining the integrity of the epithelial barriers, such as the respiratory tract, ${ }^{21}$ skin, ${ }^{26}$ and intestine. ${ }^{31}$ Compared with the untreated group, we found a fourfold increase in ILC2s 18 hours after epithelial wounding in a corneal abrasion model (Figure 2A). Next, to analyze the effect of depleting ILC2s, we subconjunctivally injected anti-CD90.2 antibody or isotype IgG. The anti-CD90.2 antibody effectively depletes ILC2s in the respiratory tract mucosa and skin of mice. ${ }^{21,26}$ Successful depletion of ILC2s in the cornea was achieved after five injections of anti-CD90.2 antibodies (Figure 2B). Compared with the isotype IgG control group, anti-CD90.2 antibody treatment delayed corneal epithelial wound healing. The wounds of the isotype IgG control group closed within 24 hours, whereas those of the anti-CD90.2 antibody-treated group did not. Further analysis revealed that epithelial thickness of anti-CD90.2 antibody-treated mice was thinner than that of isotype $\operatorname{IgG}$ control group from
48 hours to 120 hours after wounding (Figure 3A). Moreover, many coupled cell nuclei were present in the corneal epithelium, indicating that these cells are dividing, but the number of dividing epithelial cells in anti-CD90.2 antibody-treated mice was significantly lower than that in isotype $\mathrm{IgG}-$ treated mice at 18 and 24 hours after wounding (Figure 3B).

\section{Adoptive Transfer of ILC2s Partially Restores Corneal Healing in Anti-CD90.2 Antibody-Treated Mice}

Because some natural killer (NK) cells can also express CD90.2 when they are activated by stimulants, delay of corneal epithelial wound healing with anti-CD90.2 antibody injection may not be exclusively attributable to ILC2 depletion. Therefore, to verify that the delay in corneal wound healing was closely related with ILC2 depletion, we reconstituted lung ILC2s in anti-CD90.2 antibody-treated mice. Lung CD $45^{+} \mathrm{Lin}^{-} \mathrm{CD} 127^{+} \mathrm{T} 1 / \mathrm{ST} 2^{+}$ILC2s from normal mice were sorted and incubated with CFDA-SE to allow the migration of these cells to be observed. After corneal epithelial wounding of anti-CD90.2 antibody-treated mice, labeled ILC2s were injected i.v. into those mice. At 24 hours after transfer, corneal whole-mount immunostaining revealed that some injected ILC2s had already migrated to the corneal limbus (Figure 4A). After the anti-CD90.2 antibody treatment, the speed of epithelial wound closure in mice with 

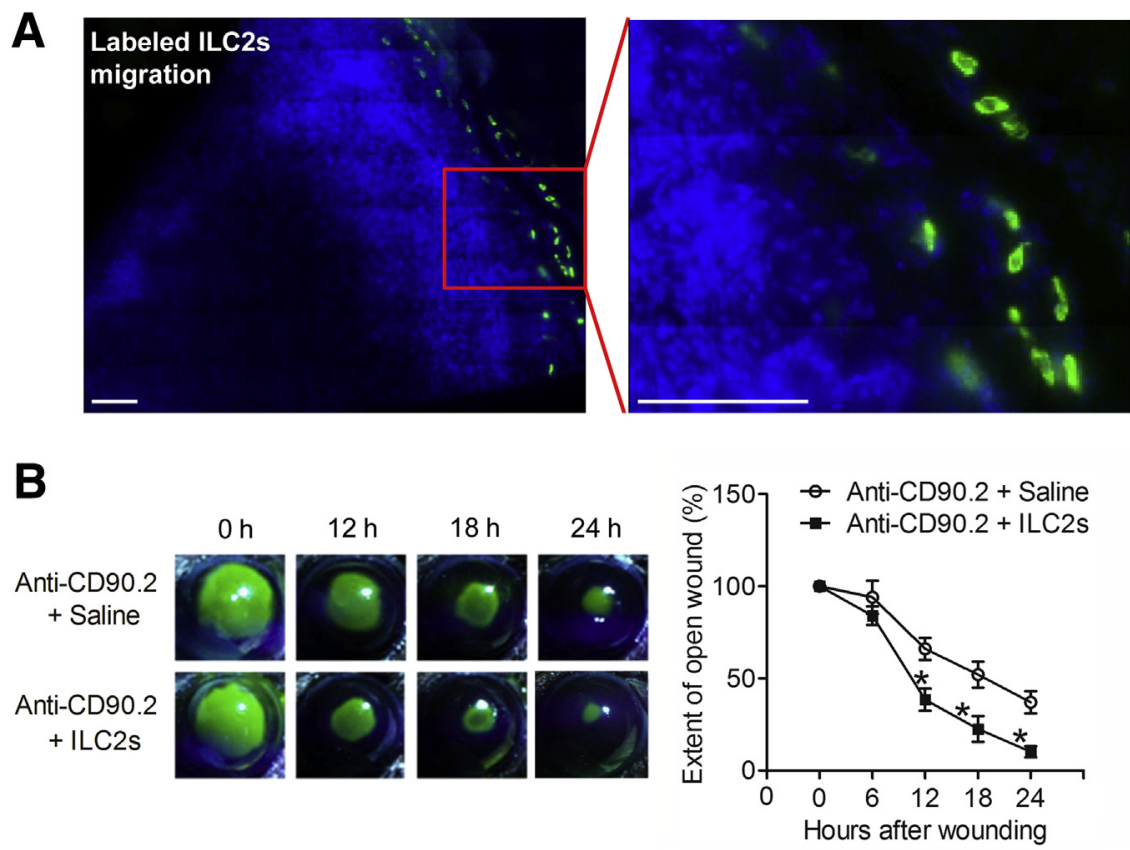

$96 \mathrm{~h}$ after wounding
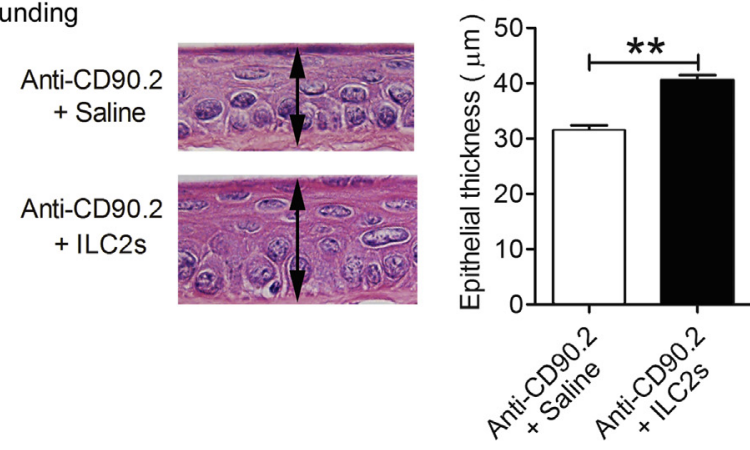

Figure 4 The effect of adoptive transfer of innate lymphoid cells (ILCS) on corneal wound closure. A: After corneal epithelial wounding, antiCD90.2 antibody-treated mice were injected i.v. with sorted lung ILC2s stained by carboxyfluorescein diacetate succinimidyl ester. Corneas of those mice stained with DAPI were visualized using fluorescence microscopy 24 hours after injection. B: Corneal epithelial wounds were stained with sodium fluorescein (upper left images). The percentage of open wound at each time point was calculated as shown. Corneal epithelium was stained with hematoxylin and eosin (lower left images), and the thickness of epithelium (double arrows) was measured using Photoshop CS4. Data are expressed as means \pm SD (B). $n=6$ mice at each time point (B). ${ }^{*} P<0.05$, ${ }^{*} P<0.01$. Scale bar $=100 \mu \mathrm{m}$. TSLP, thymic stromal lymphopoietin. reconstituted ILC2 was faster than in saline-injected control mice. Moreover, epithelial thickness of the reconstituted ILC2s group was increased compared with that of the salineinjected control group at 96 hours after wounding (Figure 4B).

\section{AREG Promotes Corneal Wound Healing in ILC2-Depleted Mice}

AREG, a member of the epidermal growth factor family, is involved in regulating tissue remodeling and repair after acute epithelial injury. ${ }^{32,33}$ Using qPCR analysis of flow cytometry-sorted corneal ILC2s, we found that ILC2s express Areg and that Areg expression increased significantly between 6 and 18 hours after corneal epithelial wounding. In contrast, after anti-CD90.2 antibody treatment, the total expression of Areg in the cornea was significantly decreased when compared with isotype IgG-treated mice (Figure 5A). To test whether AREG is the main mediator of ILC2dependent effects during corneal wound healing, recombinant AREG was ocularly administered to anti-CD90.2 antibody-treated mice. As expected, ILC2-depleted mice treated with AREG had an increased speed of epithelial wound closure compared with mice given PBS (Figure 5B).

\section{IL-25, IL-33, and TSLP Have Critical Roles in Corneal ILC2 Responses}

Because ILC2s at other locations are known to respond to IL25, IL-33, and TSLP and produce type 2 cytokines IL-4, IL-5, IL-9, and IL-13 to contribute to inflammatory response, ${ }^{21,26}$ we investigated whether IL-25, IL-33, and TSLP were necessary for ILC2 responses during corneal healing process. Our qPCR analysis revealed that the expression of $I l-25, I l-33$, and $T s l p$ in corneal tissue increased after corneal epithelial wounding (Figure 6A). We speculated that this increase may underlie the increase in the number of corneal ILC2s. To confirm this, we subconjunctivally injected anti-IL-25, -IL-33, or -TSLP antibodies to block the function of these cytokines in the cornea. At 18 hours after wounding, the total number of corneal ILC2s in the anti-IL-25, -IL-33, and -TSLP antibody-treated mice were all significantly lower than in the control group (Figure 6B). Regarding the expression of IL-4, IL-5, IL-9, and IL-13, qPCR analysis of flow cytometry-sorted corneal ILC2s 
A

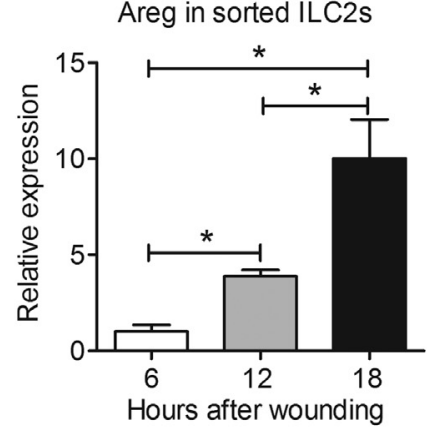

B

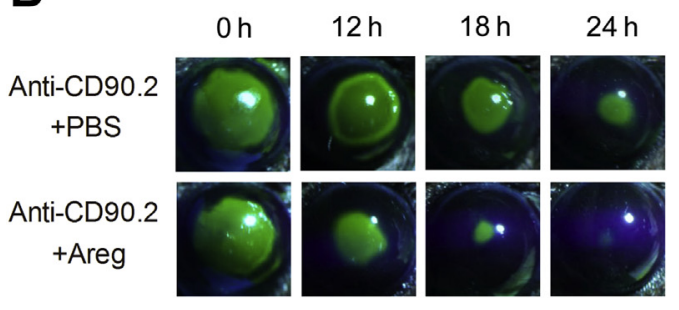

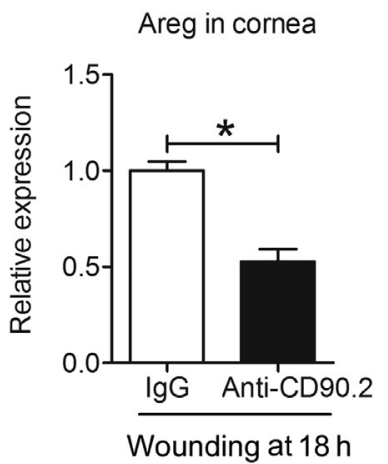

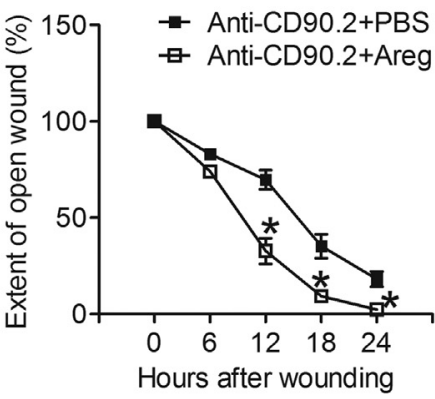

Figure 5 Amphiregulin (Areg) is produced by corneal innate lymphoid cells (ILCs) and can restore corneal wound healing in ILC2-depleted mice. A: Expression of Areg mRNA was analyzed by real-time quantitative PCR (qPCR) in sorted corneal ILC2s after corneal epithelial wounding. Expression levels are shown relative to the measurement for the 6 hours after corneal wounding group, which served as a control. Areg expression in the cornea from IgG (control)-treated and anti-CD90.2-treated mice was measured by qPCR. Expression levels are shown relative to the measurement for the IgG group, which served as a control. B: Recombinant mouse Areg or phosphate-buffered saline was given to anti-CD90.2 antibody-treated mice ocularly, four times (one topical drop given every 6 hours after corneal wounding). Corneal epithelial wounds were stained with sodium fluorescein. The percentage of open wound at each time point was calculated as shown. Data are expressed as means \pm SD. $n=3$ independent experiments (20 mice per experiment, left panel; 6 mice per experiment, right panel) (A); $n=6$ mice at each time point (B). ${ }^{*} P<0.05$. revealed that only $\mathrm{Il}-5$ and $\mathrm{Il}-13$ were expressed in corneal ILC2s (Figure 6B), and their expression in corneal tissues decreased after treatment with anti-IL-25, -IL-33, and -TSLP antibodies (Figure 6B). In addition, anti-IL-25, -IL-33, and -TSLP antibody treatment all significantly delayed corneal wound healing: the corneal wounds of isotype IgG-treated mice closed within 24 hours, whereas those of antibody-treated mice did not, and the epithelial thickness of antibody-treated mice was reduced compared with IgG-treated mice at 96 hours after wounding (Figure 6C).

\section{Depletion of CCR2 ${ }^{-}$Macrophages Decreases IL-33 Expression in the Cornea}

For the production of IL-33, macrophages and epithelial cells can secrete IL-33. Mizutani et $\mathrm{al}^{34}$ confirmed that alveolar macrophages are important producers of IL-33 in lung tissue. Depletion of alveolar macrophages using chloroadenosine resulted in significantly decreased IL-33 expression in the lung tissue. Furthermore, Nabe et $\mathrm{al}^{35}$ found that nearly $20 \%$ of the IL-33-producing cells in the lungs were M2 (alternative activation state) macrophages. In our research on macrophages, we found that the macrophages present in the cornea and corneal macrophages can be divided into two groups: $\mathrm{CD} 64^{+} \mathrm{CCR} 2^{+}$macrophages that expressed the representative genes of M1 type and $\mathrm{CD} 64^{+} \mathrm{CCR} 2^{-}$macrophages that expressed the representative genes of $\mathrm{M} 2$ type. $\mathrm{CCR} 2^{+}$and $\mathrm{CCR} 2^{-}$corneal macrophages can be depleted by a CCR2 antagonist (BMS CCR2 22) and anti-CSF1R antibody, respectively. ${ }^{36}$ Further studies indicated that neither $\mathrm{CCR} 2^{+}$nor $\mathrm{CCR} 2^{-}$corneal macrophages expressed IL-33 at a steady state, whereas
$31 \%$ of CCR2 $2^{-}$corneal macrophages started to express IL3318 hours after corneal epithelial wounding (Figure 7A). The qPCR analysis revealed that the total expression of IL33 in the cornea, from anti-CSF1R antibody-treated mice 18 hours after corneal epithelial wounding, had obviously decreased. In contrast, the expression of IL-33 did not significantly decrease after BMS CCR2 22 injection (Figure 7B).

\section{Corneal ILC2s Are Maintained by Local Proliferation at a Steady State or After Trauma}

Some tissue-resident leukocytes have the local proliferation ability, and their long-term maintenance requires few or no bone marrow progenitors. Flow cytometric analysis revealed that $24.3 \%$ of corneal ILC2s were positive for the cell proliferation marker Ki-67 (Figure 8A), indicating that these cells have the ability to locally proliferate. It was unclear, however, whether the long-term maintenance of corneal ILC2s requires bone marrow progenitor migration and differentiation. To address this question, we developed a bone marrow transplantation model in which bone marrow from Rosa-YFP male mice was used to reconstitute irradiated C57BL/6 female mice, and the Sry gene, located on the Y chromosome, was used as a marker for reconstitution. At 1 month after bone marrow transplantation, the Sry gene was found to be expressed in peripheral blood leukocytes from recipient female mice (Supplemental Figure S2A), indicating successful bone marrow transplantation. Furthermore, wild-type female mice did not have $\mathrm{YFP}^{+}$cells in their peripheral blood, but the percentage of $\mathrm{YFP}^{+}$cells in the peripheral blood 
A

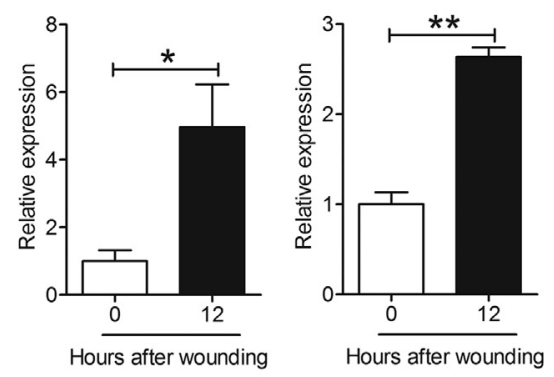

TSLP in cornea

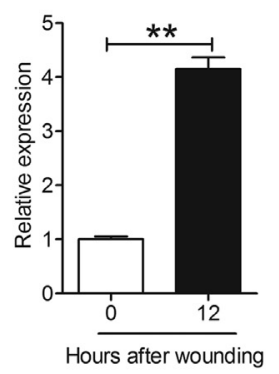

B
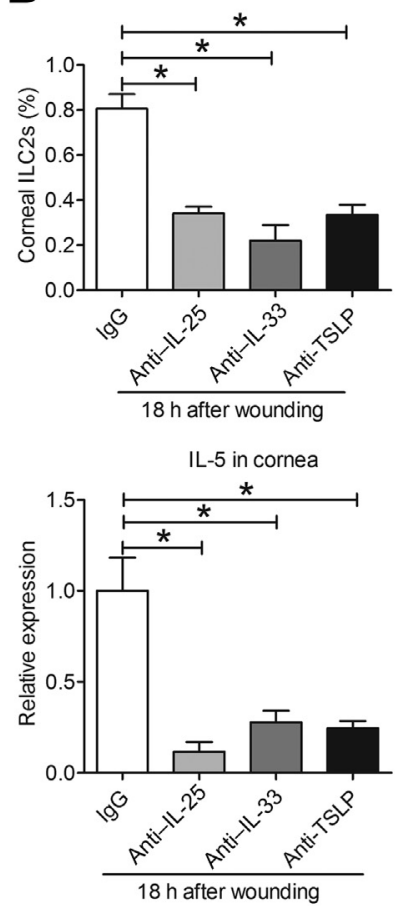

IL-5 in sorted ILC2S

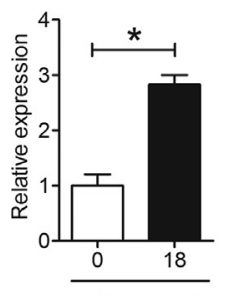

Hours after wounding
IL-13 in sorted ILC2S

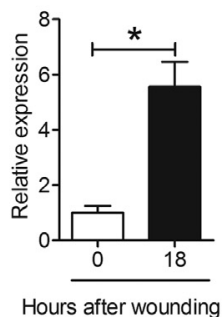

C
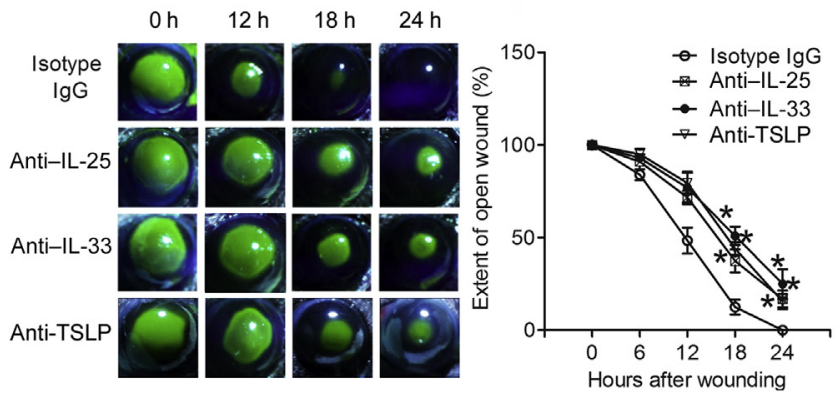

$96 \mathrm{~h}$ after wounding
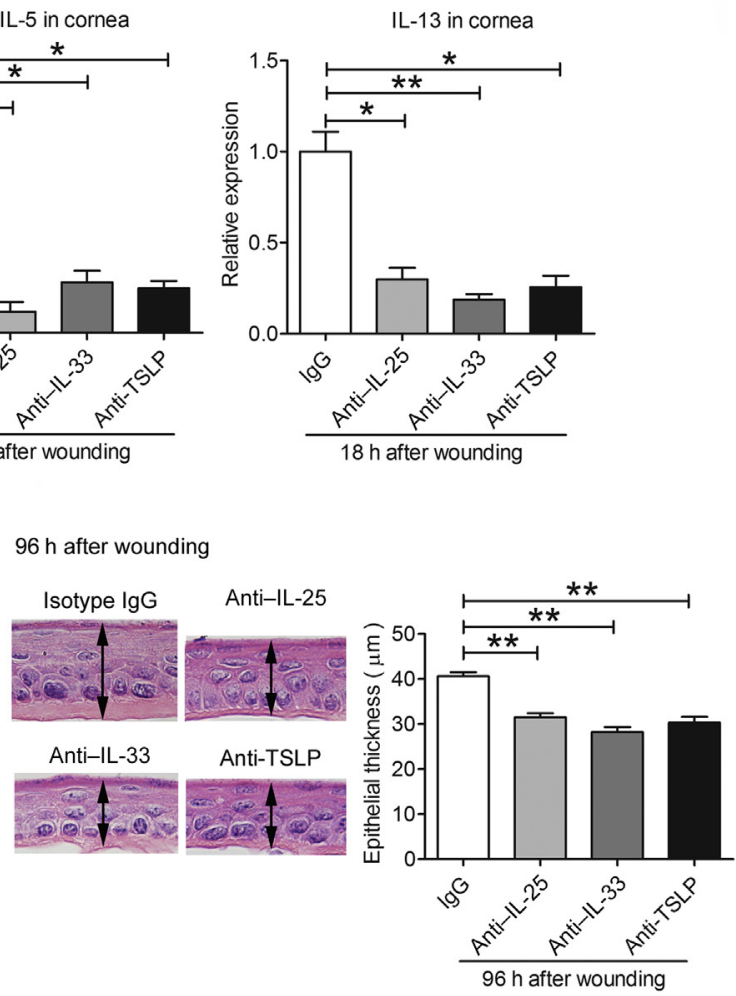

Figure 6 Participation of innate lymphoid cells (ILCs) in corneal epithelial wound healing is dependent on IL-25, IL-33, and thymic stromal lymphopoietin (TSLP). A: IL-25, IL-33, and TSLP mRNA expression were measured in corneal tissues at 0 and 12 hours after corneal epithelial abrasion. Expression levels are given relative to the measurement for the 0 hour after epithelial wounding, which served as a control. B: Anti-IL-25, -IL-33, or -TSLP antibody or isotype IgG were subconjunctivally injected 10 times (one injection every other day). The percentage of ILC2s in corneal cells (including central corneal and corneal limbal cells) from mice 18 hours after corneal wounding was determined by flow cytometry. IL-5 and IL-13 mRNA expression was measured in flow cytometry-sorted corneal ILC2s at 0 and 18 hours after corneal epithelial abrasion. Expression levels are given relative to the measurement for the 0 hour after epithelial wounding, which served as a control. IL-5 and IL-13 mRNA expression were measured in corneal tissues from isotype IgG or anti-IL-25, -IL-33, and -TSLP antibody-treated mice at 18 hours after corneal epithelial wounding. Expression levels are shown relative to IgG-treated group, which served as a control ( $n=3$ independent experiments, six mice per experiment). C: After injection of anti-IL-25, -IL-33, or -TSLP antibody or isotype IgG 10 times, respectively, a portion of corneal epithelium was abraded and epithelial wounds were stained with sodium fluorescein at the indicated time points (left images) and the percentage of open wound at each time point was calculated as shown. Corneal epithelium were stained with hematoxylin and eosin (right images), and the thickness of epithelium (double arrows) was measured using Photoshop CS4. Data are expressed as means \pm SD. $n=3$ independent experiments (six mice per experiment) (A); $n=3$ independent experiments (20 mice per experiment, top panels; and 6 mice per experiment, bottom panels) (B); $n=6$ mice at each time point $(\mathbf{C}) .{ }^{*} P<0.05,{ }^{*} P<0.01$.

leukocytes of recipient female mice reached $94 \%$ (Supplemental Figure S2B). In this model, at 3 months after bone marrow transplantation, flow cytometric analysis revealed that only $6.2 \%$ of corneal ILC2s were $\mathrm{YFP}^{+}$, indicating that $93.8 \%$ of the ILC2s were still derived from the host (Figure 8A).
Some tissue-resident macrophages are known to use distinct maintenance mechanisms at a steady state and during inflammation. ${ }^{24} \mathrm{We}$ therefore determined whether the maintenance mechanism used by corneal ILC2s changed after corneal wounding. We found that although the number of corneal ILC2s increased at 18 hours after corneal 

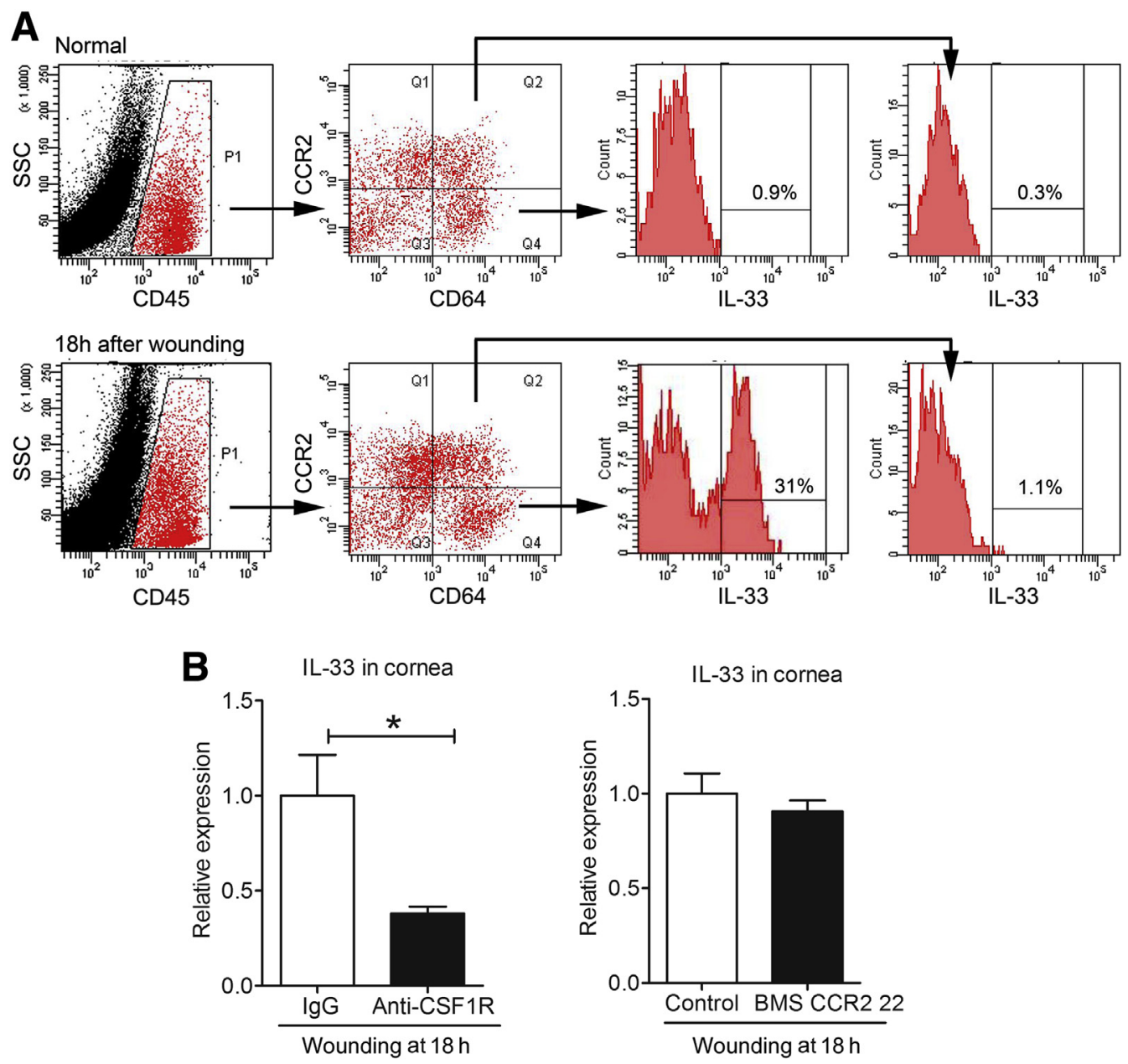

Figure 7 The effect of macrophage depletion on IL-33 expression in corneas. A: Analysis of IL-33 expression in corneal macrophages. CD45 ${ }^{+}$leukocytes (P1 gated) from corneal cells were analyzed by CD64 and CCR2 to obtain CD64 ${ }^{+} \mathrm{CCR}^{+}$(Q2 gated) and CD64 ${ }^{+} \mathrm{CCR}^{-}$(Q4 gated) macrophages. Then, $\mathrm{CCR} 2^{+}$and CCR2 ${ }^{-}$macrophages were further analyzed by the expression of IL-33. The gating strategies were justified by appropriate isotype control antibodies, which were provided in the Supplemental Figure S1B. B: Changes in IL-33 expression in corneas after mice being injected with anti-CSF1R antibody or BMS CCR2 22. Data are expressed as means \pm SD (B). $n=3$ independent experiments (each experiment contained six mice). ${ }^{*} P<0.05$. FSC, forward scatter; SSC, side scatter.

epithelial wounding (Figure 2), the percentage of $\mathrm{YFP}^{+}$cells in corneal ILC2s remained low (8.3\%), indicating that the most ILC2s were still host derived. Moreover, after corneal epithelial wounding, the percentage of $\mathrm{Ki}-67^{+}$cells in corneal ILC2s increased from $24.3 \%$ to $41.9 \%$ (Figure 8 B).

\section{Discussion}

ILCs have been detected in embryonic tissue, bone marrow, secondary lymphoid organs, lung tissue, the small intestine, and skin tissue, with different types of ILC residing in different locations. ${ }^{12,26,37}$ In this study, we confirmed the existence of ILC2s in the corneal limbus. Moreover, we found that ILC2s promoting corneal epithelial wound healing depend on local induction of IL-25, IL-33, and TSLP and that CCR2 ${ }^{-}$corneal macrophages are an important source of IL-33. Using a bone marrow transplantation model, we found that long-term maintenance of ILC2s in the cornea can be accomplished primarily through local proliferation.

Our study first confirmed that a small number of ILCs residing in the corneal limbus are $\mathrm{CD} 45^{+} \mathrm{Lin}^{-} \mathrm{CD} 127^{+} \mathrm{T} 1 /$ $\mathrm{ST}^{+} \mathrm{cKit}^{+} \mathrm{CD}^{+} 0^{+}$, which are usually used to detect ILC2s. Research in mice conducted by Monticelli et $\mathrm{al}^{21}$ revealed that after infection with influenza virus, ILC2s quickly gathered at the site of infection within the respiratory tract and lungs, where they promoted restoration of the damaged tissues. Compared with wild-type mice, depletion of ILC2s in infected mice resulted in decreased integrity of the respiratory tract and lung function. Similarly, our analysis of the cornea reveals an increase of ILC2s after epithelial abrasion, suggesting that ILC2s may be involved in the process of corneal epithelial wound healing. After applying the anti-CD90.2 antibody, both the speed of corneal wound closure and the division rate of epithelial 


\section{A}

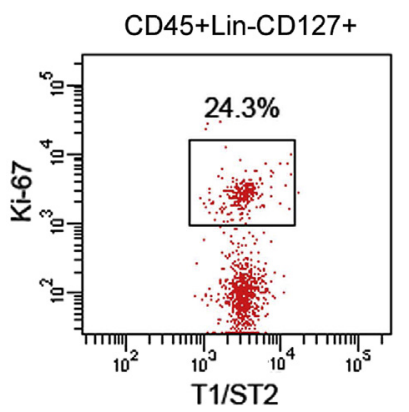

steady state

B

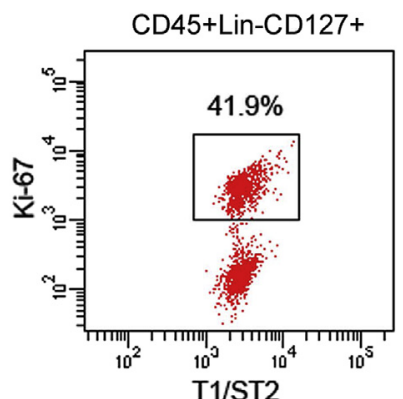

$18 \mathrm{~h}$ after wounding

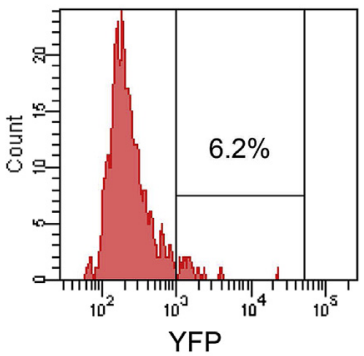

YFP

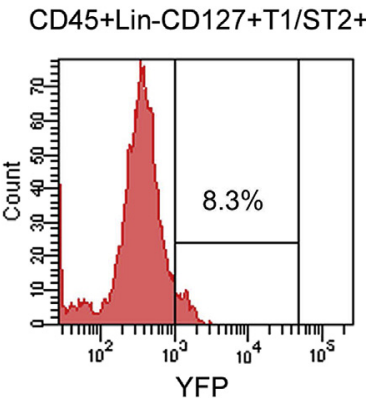

Figure 8 Proliferation of corneal innate lymphoid cells (ILCS) at a steady state and after wounding. A: Three months after transplantation of bone marrow from Rosa-yellow fluorescent protein (YFP) male mice, the percentage of $\mathrm{Ki}-67^{+}$and $\mathrm{YFP}^{+}$cells in corneal ILC2s was measured using flow cytometry. B: The percentage of Ki- $67^{+}$and YFP ${ }^{+}$cells in corneal ILC2s was determined at 18 hours after corneal epithelial wounding. The gating strategies were justified by related isotype control antibodies or corneal ILC2s from wild-type female mice, which were provided in the Supplemental Figure S1C.

cells decreased. Although some NK cells, which expressed CD90.2 when activated, may also be depleted by antiCD90.2 antibody injection, the delay in corneal epithelial restoration could be mitigated by reconstitution of ILC2s via adoptive transfer of these cells. These findings indicate that ILC2s can promote corneal healing after epithelial abrasion and that deficiency of these cells delays the healing process.

The qPCR analysis of sorted corneal ILC2s indicated that these cells expressed Areg and that Areg expression increased after epithelial abrasion. In contrast, Areg expression in the cornea decreased significantly when corneal ILC2s were depleted, indicating that ILC2s have an important role in the production of AREG in the cornea. Interestingly, topical treatment with recombinant mouse AREG can restore the healing speed of damaged cornea in ILC2-depleted mice. Therefore, AREG secretion is one ILC2 pathway that promotes corneal healing.

The activation of immune cells typically depends on cytokine stimulation; for example, corneal epithelial cell-secreted CCL20 is necessary for $\gamma \delta \mathrm{T}$ cell migration and activation. ${ }^{6}$ Our analysis revealed that $I l 25, I l 33$, and Tslp are expressed in the cornea and that their expression increased after epithelial abrasion. Compared with the untreated control group, there was a decrease in the number of ILC2s in anti-IL-25, -IL-33, or -TSLP antibody-treated mice after epithelial wounding. Moreover, corneal ILC2s expressed type 2 cytokines, Il-5, and Il-13. ILC2derived IL-5 can recruit eosinophils to tissue sites, ${ }^{38-40}$ and eosinophils contribute to injured airway remodeling. ${ }^{41}$ IL-13 has been reported to control profibrotic responses during repair process of damaged skin and other tissues. ${ }^{42,43}$ However, the expression of the two cytokines was found to be decreased after anti-IL-25, -IL-33, or -TSLP antibody injection. Therefore, blocking of IL-25, IL-33, and TSLP hindered the activation of corneal ILC2s and delayed the corneal epithelial wound healing. Together, these results suggest that ILC2 responses during corneal wound healing depend on IL-25, IL-33, and TSLP stimulation.

After tissues have been damaged, epithelial cells are considered as the important cells to produce IL-33. However, a recent study indicated that macrophages can also secrete IL-33. ${ }^{34}$ However, because of the heterogeneity of macrophages, it is still unclear which subset of macrophages produces IL-33 in certain tissues. In this study, we found that CCR2 ${ }^{-}$corneal macrophages were able to produce IL33 after epithelial wounding. When this group of cells was depleted, the expression of Il33 decreased in the cornea. Therefore, $\mathrm{CCR}^{-}$corneal macrophages constitute an important source of IL-33 in the cornea, indicating that CCR2 ${ }^{-}$macrophages may modulate ILC2 responses through IL-33 secretion. Thus, this finding provides information regarding the association between macrophages and ILC2s in corneal wound healing.

Tissue-resident macrophages can be categorized into two groups according to their origin and maintenance mechanisms. One group comprised cells that settled in peripheral tissues during the early embryonic period; macrophages are the typical cells that have this biologic characteristic. These macrophages' long-term maintenance relies on local proliferation. ${ }^{44}$ The other group of macrophages migrated to tissues during the later embryonic stage or after birth and require a continuous supply of hematopoietic progenitors for renewal. ${ }^{24}$ Flow cytometric analysis indicated that corneal ILC2s possess the ability to locally proliferate. Using the bone marrow transplantation model, we found that at a steady state and after wounding, the percentage of donor cells in corneal ILC2s is always low and local proliferation capacity of corneal ILC2s increases after epithelial wounding. Therefore, corneal ILC2s are mainly maintained and expanded by local proliferation both at a steady state and after wounding. Thus, corneal ILC2s are similar to the first group of cells in terms of long-term maintenance through self-proliferation, but further work is needed to determine whether these cells settle in the cornea during the early embryonic period.

Collectively, our results indicate that ILC2s exist in the corneal limbi, where they promote corneal regeneration after corneal abrasion. Furthermore, the function of corneal ILC2s in the healing process relies on local induction of 
IL-25, IL-33, and TSLP, and of these, IL-33 can be produced by $\mathrm{CCR} 2^{-}$corneal macrophages (Supplemental Figure S3). In addition, the long-term maintenance of corneal ILC2s mainly depends on local proliferation and rarely depends on the contribution of bone marrow progenitor cells. These findings shed light on the role of ILC2s in corneal wound healing and indicate a new potential therapeutic target for the clinical treatment of defective corneal repair, such as caused by diabetes and chronic microbial infection.

\section{Acknowledgments}

Z.L. and J.L. conceived and designed the study; J.L. and C.X. analyzed immunostaining; H.W., Y.X., D.D., C.L., F.S., T.F., and Z.W. helped with treatment of the animals, including drug treatment, corneal epithelial wounding, and bone marrow transplantation; J.L. performed qPCR and flow cytometry analysis; J.C., H.P., Y.L., and D.C. conducted the statistical analysis; J.L. drafted the first version of the paper; Z.L. critically reviewed and revised the paper for intellectual content; and all the authors critiqued the manuscript and approved its submission.

\section{Supplemental Data}

Supplemental material for this article can be found at http://dx.doi.org/10.1016/j.ajpath.2017.02.010.

\section{References}

1. Robaei D, Watson S: Corneal blindness: a global problem. Clin Exp Ophthalmol 2014, 42:213-214

2. Furtado JM, Lansingh VC, Carter MJ, Milanese MF, Pena BN, Ghersi HA, Bote PL, Nano ME, Silva JC: Causes of blindness and visual impairment in Latin America. Surv Ophthalmol 2012, 57: $149-177$

3. Reinke JM, Sorg H: Wound repair and regeneration. Eur Surg Res 2012, 49:35-43

4. Babcock DT, Brock AR, Fish GS, Wang Y, Perrin L, Krasnow MA, Galko MJ: Circulating blood cells function as a surveillance system for damaged tissue in Drosophila larvae. Proc Natl Acad Sci U S A 2008, 105:10017-10022

5. Niethammer P, Grabher C, Look AT, Mitchison TJ: A tissue-scale gradient of hydrogen peroxide mediates rapid wound detection in zebrafish. Nature 2009, 459:996-999

6. Li Z, Burns AR, Miller SB, Smith CW: CCL20, gammadelta T cells, and IL-22 in corneal epithelial healing. FASEB J 2011, 25:2659-2668

7. Li Z, Burns AR, Han L, Rumbaut RE, Smith CW: IL-17 and VEGF are necessary for efficient corneal nerve regeneration. Am J Pathol 2011, 178:1106-1116

8. Li Z, Burns AR, Rumbaut RE, Smith CW: gamma delta T cells are necessary for platelet and neutrophil accumulation in limbal vessels and efficient epithelial repair after corneal abrasion. Am J Pathol 2007, 171:838-845

9. Byeseda SE, Burns AR, Dieffenbaugher S, Rumbaut RE, Smith CW, Li Z: ICAM-1 is necessary for epithelial recruitment of gammadelta T cells and efficient corneal wound healing. Am J Pathol 2009, 175: 571-579
10. Li Z, Burns AR, Smith CW: Two waves of neutrophil emigration in response to corneal epithelial abrasion: distinct adhesion molecule requirements. Invest Ophthalmol Vis Sci 2006, 47: 1947-1955

11. Liu Q, Smith CW, Zhang W, Burns AR, Li Z: NK cells modulate the inflammatory response to corneal epithelial abrasion and thereby support wound healing. Am J Pathol 2012, 181:452-462

12. Artis D, Spits H: The biology of innate lymphoid cells. Nature 2015, 517:293-301

13. Spits H, Cupedo T: Innate lymphoid cells: emerging insights in development, lineage relationships, and function. Annu Rev Immunol 2012, 30:647-675

14. Vivier E, Raulet DH, Moretta A, Caligiuri MA, Zitvogel L, Lanier LL, Yokoyama WM, Ugolini S: Innate or adaptive immunity? the example of natural killer cells. Science 2011, 331:44-49

15. Mjosberg JM, Trifari S, Crellin NK, Peters CP, van Drunen CM, Piet B, Fokkens WJ, Cupedo T, Spits H: Human IL-25- and IL-33responsive type 2 innate lymphoid cells are defined by expression of CRTH2 and CD161. Nat Immunol 2011, 12:1055-1062

16. Mjosberg J, Bernink J, Golebski K, Karrich JJ, Peters CP, Blom B, te Velde AA, Fokkens WJ, van Drunen CM, Spits H: The transcription factor GATA3 is essential for the function of human type 2 innate lymphoid cells. Immunity 2012, 37:649-659

17. Mebius RE, Rennert P, Weissman IL: Developing lymph nodes collect CD4 + CD3- LTbeta + cells that can differentiate to APC, NK cells, and follicular cells but not T or B cells. Immunity 1997, 7:493-504

18. Yoshida H, Honda K, Shinkura R, Adachi S, Nishikawa S, Maki K, Ikuta K, Nishikawa SI: IL-7 receptor alpha+ CD3(-) cells in the embryonic intestine induces the organizing center of Peyer's patches. Int Immunol 1999, 11:643-655

19. Lee JS, Cella M, McDonald KG, Garlanda C, Kennedy GD, Nukaya M, Mantovani A, Kopan R, Bradfield CA, Newberry RD, Colonna M: AHR drives the development of gut ILC22 cells and postnatal lymphoid tissues via pathways dependent on and independent of Notch. Nat Immunol 2012, 13:144-151

20. Zheng Y, Valdez PA, Danilenko DM, Hu Y, Sa SM, Gong Q, Abbas AR, Modrusan Z, Ghilardi N, de Sauvage FJ, Ouyang W: Interleukin-22 mediates early host defense against attaching and effacing bacterial pathogens. Nat Med 2008, 14:282-289

21. Monticelli LA, Sonnenberg GF, Abt MC, Alenghat T, Ziegler CG, Doering TA, Angelosanto JM, Laidlaw BJ, Yang CY, Sathaliyawala T, Kubota M, Turner D, Diamond JM, Goldrath AW, Farber DL, Collman RG, Wherry EJ, Artis D: Innate lymphoid cells promote lungtissue homeostasis after infection with influenza virus. Nat Immunol 2011, 12:1045-1054

22. Chorro L, Sarde A, Li M, Woollard KJ, Chambon P, Malissen B, Kissenpfennig A, Barbaroux J-B, Groves R, Geissmann F: Langerhans cell (LC) proliferation mediates neonatal development, homeostasis, and inflammation-associated expansion of the epidermal LC network. J Exp Med 2009, 206:3089-3100

23. Ajami B, Bennett JL, Krieger C, Tetzlaff W, Rossi FM: Local selfrenewal can sustain CNS microglia maintenance and function throughout adult life. Nat Neurosci 2007, 10:1538-1543

24. Epelman S, Lavine KJ, Beaudin AE, Sojka DK, Carrero JA, Calderon B, Brija T, Gautier EL, Ivanov S, Satpathy AT, Schilling JD, Schwendener R, Sergin I, Razani B, Forsberg EC, Yokoyama WM, Unanue ER, Colonna M, Randolph GJ, Mann DL: Embryonic and adult-derived resident cardiac macrophages are maintained through distinct mechanisms at steady state and during inflammation. Immunity 2014, 40:91-104

25. Gasteiger G, Fan X, Dikiy S, Lee SY, Rudensky AY: Tissue residency of innate lymphoid cells in lymphoid and nonlymphoid organs. Science 2015, 350:981-985

26. Rak GD, Osborne LC, Siracusa MC, Kim BS, Wang K, Bayat A, Artis D, Volk SW: IL-33-dependent group 2 innate lymphoid cells promote cutaneous wound healing. J Invest Dermatol 2016, 136: 487-496 
27. Liu J, Fu T, Song F, Xue Y, Xia C, Liu P, Wang H, Zhong J, Li Q, Chen J, Li Y, Cai D, Li Z: Mast cells participate in corneal development in mice. Sci Rep 2015, 5:17569

28. Halim TY, Takei F: Isolation and characterization of mouse innate lymphoid cells. Curr Protoc Immunol 2014, 106:3.25.1-3.25.13

29. Spits H, Artis D, Colonna M, Diefenbach A, Di Santo JP, Eberl G, Koyasu S, Locksley RM, McKenzie AN, Mebius RE, Powrie F, Vivier E: Innate lymphoid cells-a proposal for uniform nomenclature. Nat Rev Immunol 2013, 13:145-149

30. Spits H, Di Santo JP: The expanding family of innate lymphoid cells: regulators and effectors of immunity and tissue remodeling. Nat Immunol 2011, 12:21-27

31. von Moltke J, Ji M, Liang HE, Locksley RM: Tuft-cell-derived IL-25 regulates an intestinal ILC2-epithelial response circuit. Nature 2016, 529:221-225

32. Enomoto Y, Orihara K, Takamasu T, Matsuda A, Gon Y, Saito H, Ra C, Okayama Y: Tissue remodeling induced by hypersecreted epidermal growth factor and amphiregulin in the airway after an acute asthma attack. J Allergy Clin Immunol 2009, 124:913-920

33. Fukumoto J, Harada C, Kawaguchi T, Suetsugu S, Maeyama T, Inoshima I, Hamada N, Kuwano K, Nakanishi Y: Amphiregulin attenuates bleomycin-induced pneumopathy in mice. Am J Physiol Lung Cell Mol Physiol 2010, 298:L131-L138

34. Mizutani N, Nabe T, Yoshino S: Interleukin-33 and alveolar macrophages contribute to the mechanisms underlying the exacerbation of IgE-mediated airway inflammation and remodelling in mice. Immunology 2013, 139:205-218

35. Nabe $T$, Wakamori $H$, Yano $C$, Nishiguchi A, Yuasa R, Kido $H$, Tomiyama Y, Tomoda A, Kida H, Takiguchi A, Matsuda M, Ishihara K, Akiba S, Ohya S, Fukui H, Mizutani N, Yoshino S: Production of interleukin (IL)-33 in the lungs during multiple antigen challenge-induced airway inflammation in mice, and its modulation by a glucocorticoid. Eur J Pharmacol 2015, 757:34-41
36. Liu J, Xue Y, Dong D, Xiao C, Lin C, Wang H, Song F, Fu T, Wang Z, Chen J, Pan H, Li Y, Cai D, Li Z: CCR2- and CCR2+ corneal macrophages exhibit distinct characteristics and balance inflammatory responses after epithelial abrasion. Mucosal Immunol 2017, [Epub ahead of print] doi:10.1038/mi.2016.139

37. Eberl G, Colonna M, Di Santo JP, McKenzie AN: Innate lymphoid cells: a new paradigm in immunology. Science 2015, 348:aaa6566

38. Molofsky AB, Nussbaum JC, Liang HE, Van Dyken SJ, Cheng LE, Mohapatra A, Chawla A, Locksley RM: Innate lymphoid type 2 cells sustain visceral adipose tissue eosinophils and alternatively activated macrophages. J Exp Med 2013, 210:535-549

39. Nussbaum JC, Van Dyken SJ, von Moltke J, Cheng LE, Mohapatra A, Molofsky AB, Thornton EE, Krummel MF, Chawla A, Liang HE, Locksley RM: Type 2 innate lymphoid cells control eosinophil homeostasis. Nature 2013, 502:245-248

40. Roediger B, Kyle R, Yip KH, Sumaria N, Guy TV, Kim BS, Mitchell AJ, Tay SS, Jain R, Forbes-Blom E: Cutaneous immunosurveillance and regulation of inflammation by group 2 innate lymphoid cells. Nat Immunol 2013, 14:564-573

41. Humbles AA, Lloyd CM, McMillan SJ, Friend DS, Xanthou G, McKenna EE, Ghiran S, Gerard NP, Yu C, Orkin SH, Gerard C: A critical role for eosinophils in allergic airways remodeling. Science 2004, 305:1776-1779

42. Rankin AL, Mumm JB, Murphy E, Turner $\mathrm{S}$, Yu N, McClanahan TK, Bourne PA, Pierce RH, Kastelein R, Pflanz S: IL33 induces IL-13-dependent cutaneous fibrosis. J Immunol 2010, 184:1526-1535

43. Wynn TA: Integrating mechanisms of pulmonary fibrosis. J Exp Med 2011, 208:1339-1350

44. Hashimoto D, Chow A, Noizat C, Teo P, Beasley MB, Leboeuf M, Becker CD, See P, Price J, Lucas D: Tissue-resident macrophages selfmaintain locally throughout adult life with minimal contribution from circulating monocytes. Immunity 2013, 38:792-804 